\title{
Preparation and Characterization of Acrylic Primer for Concrete Substrate Application
}

\author{
El-Sayed Negim, ${ }^{1,2}$ Nurlybayeva Aisha, ${ }^{3}$ Grigoriy A. Mun, ${ }^{4}$ Rinat Iskakov, ${ }^{1}$ \\ Galiya S. Irmukhametova, ${ }^{4}$ and Mussylmanbek Sakhy ${ }^{3}$ \\ ${ }^{1}$ School of Chemical Engineering, Kazakh-British Technical University, 106 Walikhanov Street, Almaty 050010, Kazakhstan \\ ${ }^{2}$ Polymer \& Pigment Department, National Research Centre, 33 El Bohouth Street, Dokki, Giza 12622, Egypt \\ ${ }^{3}$ Taraz State University Named After M.H. Dulati, 60 Tole Bi Street, Taraz 080000, Kazakhstan \\ ${ }^{4}$ Department of Chemistry \& Technology of Organic Materials, Polymers and Natural Compounds, \\ Al-Farabi Kazakh National University, 71 Al-Farabi Avenue, Almaty 050040, Kazakhstan
}

Correspondence should be addressed to El-Sayed Negim; elashmawi5@yahoo.com

Received 3 December 2015; Accepted 18 January 2016

Academic Editor: Marta Fernández-García

Copyright (C) 2016 El-Sayed Negim et al. This is an open access article distributed under the Creative Commons Attribution License, which permits unrestricted use, distribution, and reproduction in any medium, provided the original work is properly cited.

\begin{abstract}
This study dealt with the properties of acrylic primer for concrete substrate using acrylic syrup, made from a methyl methacrylate monomer solution of terpolymers. Terpolymer systems consisting of methyl methacrylate (MMA), 2-ethylhexyl acrylate (2-EHA), and methacrylic acid (MAA) with different chemical composition ratios of MMA and 2-EHA were synthesized through bulk polymerization using azobisisobutyronitrile (AIBN) as initiator. The terpolymer composition is characterized by FTIR, ${ }^{1} \mathrm{H}$ NMR, DSC, TGA, and SEM. The glass transition temperature and the thermal stability increased with increasing amounts of MMA in the terpolymer backbone. The effect of chemical composition of terpolymers on physicomechanical properties of primer films was investigated. However, increasing the amount of MMA in terpolymer backbone increased tensile and contact angle of primer films while elongation at break, water absorption, and bond strength are decreased. In particular, the primer syrup containing $65 \%$ 2-EHA has good bonding strength with concrete substrate around 1.1 MPa.
\end{abstract}

\section{Introduction}

Methyl methacrylate (MMA) is an important monomer, which is widely used for producing acrylic plastics poly(methylmethacrylate) (PMMA) or producing polymer dispersions for surface coatings, adhesives, and functional additives [1-4]. However, the physical and mechanical properties of PMMA limit its applications due to its brittleness nature. In order to enhance its mechanical properties, scientists have developed various methods to prepare different types of PMMA through the copolymerization of MMA monomer with various types of vinyl monomers. In this regard, Pathak et al. [5] have prepared terpolymer films of poly(methyl methacrylate-co-styrene-co-acrylonitrile) and found that films are brittle, light yellow in color and the softening range of the films was found in the range 89$119^{\circ} \mathrm{C}$. The copolymerization of methyl methacrylate with 3,5-dimethylphenyl acrylate has been studied [6]. Glass transition temperature $\left(T_{q}\right)$ and thermal stability of the copolymer films were tested and it was found that properties of copolymer depend on the monomer composition. Increasing the content of methyl methacrylate ratio in the copolymer led to a significant increase in $T_{g}$ of the film, while thermal stability of the film enhanced by increasing 3,5-dimethylphenyl acrylate content. The same behavior was reported by Vijayanand et al. [7] when they studied properties of MMA/MAA copolymer films. Polymer films exhibited lower strength values by increasing MAA content. However, the mechanical properties of films containing 5\% mPMMA were comparable to the commercially available resin. The chemical structure and physicomechanical properties of polymers depend on the monomer units, which are distributed along the macromolecular chains [5]. On the other hand, to prepare acrylic syrup, two components selfpolymerizing, a mixture of powdered polymer and monomer, 
is used. Mixing of two components is followed by dissolution of the polymer in the monomer results in the formation of plastic dough $[8,9]$. Along with this physical interaction, the syrup is cured by the application of self-curing type. In self-curing, the polymerization reaction of methacrylate monomers is initiated by the activation reaction of benzoyl peroxide (BPO), with an amine accelerator at room temperature, which gives free radicals for addition to monomer molecules [10]. A high level of heat is generated during the exothermic reaction [9].

In the present work the terpolymer of MMA, 2-EHA, and MAA has been synthesized at various composition ratios of MMA and 2-EHA using bulk techniques. The prepared terpolymers were characterized using different instrumental techniques such as FTIR, ${ }^{1} \mathrm{H}$ NMR, TGA, DTA, DSC, and SEM. Furthermore, the effect of MMA and 2-EHA on physicomechanical properties of primer syrups was studied by usual standard procedures.

\section{Materials and Methods}

2.1. Materials. Methyl methacrylate (MMA), 2-ethyl hexyl acrylate (2-EHA), methacrylic acid (MAA) monomers, AIBN (initiator), solvents (ethanol and diethyl ether), N,Ndimethyl-p-toluidine (NDPT), benzoyl peroxide (BPO), and sodium hydroxide $(1 \mathrm{~N})$ were purchased from Fluka.

2.2. Synthesis of the Terpolymers. Terpolymerization of MMA, 2-EHA, and MAA monomers was carried out by using bulk polymerization techniques at various monomers ratios, $\mathrm{M} 1=65: 30: 5 \mathrm{wt} . \%, \mathrm{M} 2=75: 20: 5 \mathrm{wt} . \%$, and $\mathrm{M} 3$ $=80: 15: 5$ wt. $\%$, respectively, using ABIN as an initiator at $60^{\circ} \mathrm{C}$. The monomers (MMA/2-EHA/MMA) were mixed together and part of monomers was charged into a $500 \mathrm{~mL}$ three-necked flask. The free radical initiation system of AIBN $(1.5 \mathrm{~g})$ was added to the flask during mechanical stirring at $500 \mathrm{rpm}$. The other part of monomers (MMA/2-EHA/MAA) was added dropwise (about $12 \mathrm{~mL} / \mathrm{hr}$ ) during the stirring process at $65^{\circ} \mathrm{C}$ using an automatically controlled water bath under nitrogen atmosphere for a period of $4 \mathrm{hr}$ followed by another $1 \mathrm{hr}$ at $80^{\circ} \mathrm{C}$. Sodium hydroxide $(1 \mathrm{~N})$ was injected through a hypodermic needle during preparation in order to control the $\mathrm{pH}$ of the solution at $8 \pm 1$. Then, the terpolymers synthesized were reprecipitated several times from ethanol to diethyl ether and dried in vacuum desiccators at $30^{\circ} \mathrm{C}$ until a constant weight was achieved.

2.3. Primer Film Formation. Primer syrups were produced by dissolving terpolymers powder (M1, M2, and M3) into MMA monomer at normal temperature $\left(25^{\circ} \mathrm{C}\right)$ to maintain the primer syrup at $15 \%$, respectively. The viscosity of the primer syrups increases noticeably in few minutes due to partial dissolution of particles of terpolymers, in addition to the conversion of the monomeric MMA into polymer chain [8, $11,12]$. Then, primer films (M1, M2, and M3) were prepared by casting the primer syrup after mixing with initiator $\mathrm{BPO}$ and accelerator NDPT, which was added at 2.0 part and 1.0 part per hundred (pph) of terpolymers to mixtures, respectively, on leveled surfaces, allowing them to dry at $60^{\circ} \mathrm{C}$, for $2 \mathrm{~h}$.

2.4. Measurements. FTIR spectra were recorded on a Perkin Elmer 2000 FTIR spectrometer. The ${ }^{1} \mathrm{H}$ NMR spectra of the prepared terpolymers were carried out by using a JEOL EX270 NMR spectrometer, $270 \mathrm{MHz}$ Japan for ${ }^{1} \mathrm{H}$ NMR with super conducting magnet Oxford, and $5 \mathrm{~mm}$ dual probehead for ${ }^{1} \mathrm{H}$. Typical conditions spectral width $1 / 44000 \mathrm{~Hz}$ for hydrogen proton. Thermogravimetric analysis (TGA) was recorded on a TGA/SDTA851e, METTLER TOLEDO. Glass transition temperature of samples was measured using differential scanning calorimetry (DSC), on a NETZSCH DSC200 PC, using aluminum crimped pans under $\mathrm{N}_{2}$ flow at $20 \mathrm{~mL} \mathrm{~min}^{-1}$. The measurements were carried out between $-50^{\circ} \mathrm{C}$ and $200^{\circ} \mathrm{C}$ at a heating rate of $10^{\circ} \mathrm{C} \mathrm{Min}^{-1}$. The microstructure of the terpolymers was investigated by scanning electron microscopy (SEM) recorded on a CarlZeiss SMT, Oberkochen, Germany. Pot life and cure time tests were according to DIN EN ISO 9514 [13] and ASTM D589503 [14], respectively. The tensile properties of the terpolymer cast films were measured by using MTS 10/M tensile testing machine at a crosshead speed of $50 \mathrm{~mm} / \mathrm{min}$. An average of at least four measurements was taken, and the 1-kN load cell was used. Shore D hardness was measured using an indentation hardness tester according to ASTM D2240-75. Dynamic wetting tests were performed on a Camtel CDCA100F dynamic adsorption apparatus (Camtel, UK). Each sample was cut to a size of $1 \mathrm{~cm} \times 5 \mathrm{~cm}$ with sharp scissors. When the specimen was immersed into water for 6 months, the weight of adsorbed water was detected and recorded. The dynamic water adsorption was plotted as a function of feed composition of monomers. A universal testing machine (DCS-500, Shimadzu Crop, Kyoto, Japan) at a crosshead speed of $0.5 \mathrm{~mm} / \mathrm{min}$. was used to conduct the bond strength test [15-21]. The calculated bond strength was determined by dividing the force at which bond failure occurred by the bonding area.

\section{Results and Discussion}

3.1. Characterization of Terpolymers. Chemical structure of the prepared terpolymers with different composition of methyl methacrylate (MMA) and 2-ethylhexyl acrylate (2-EHA) and constant ratio of methacrylic acid (MAA) [(65:30:5), (75:20:5), and $(80: 15: 5)$ wt.\% (M1, M2, and M3)], respectively, was confirmed by FT-IR and ${ }^{1} \mathrm{H}$ NMR spectroscopy.

FTIR spectra of terpolymers are shown in Figure 1. As clearly seen, the intensity of $\mathrm{O}-\mathrm{H}$ stretching vibration of carboxylic groups which appeared in the range 3441$3414 \mathrm{~cm}^{-1}$ changes with the MAA content in the synthesized terpolymers. The $\mathrm{C}=\mathrm{O}$ stretching vibration of the acid carbonyl groups and ester groups appeared in the range 1736$1734 \mathrm{~cm}^{-1}$. Moreover, the peaks at 1242 and $1167 \mathrm{~cm}^{-1}$ are related to $\mathrm{C}-\mathrm{O}-\mathrm{C}$ stretching vibration of ester groups. The $\mathrm{CH}_{2}$ deformation vibration bands are clearly observed at $1466-1384 \mathrm{~cm}^{-1}$, while the strong vibration bands of $\mathrm{CH}_{3}$ and 


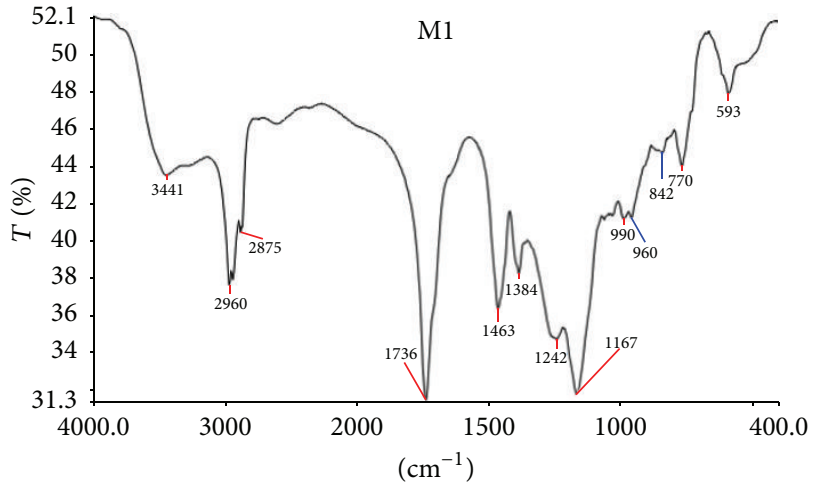

(a)

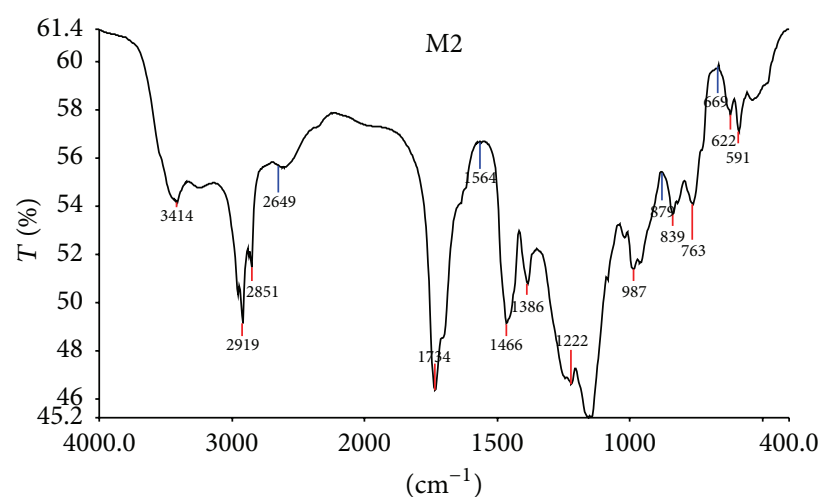

(b)

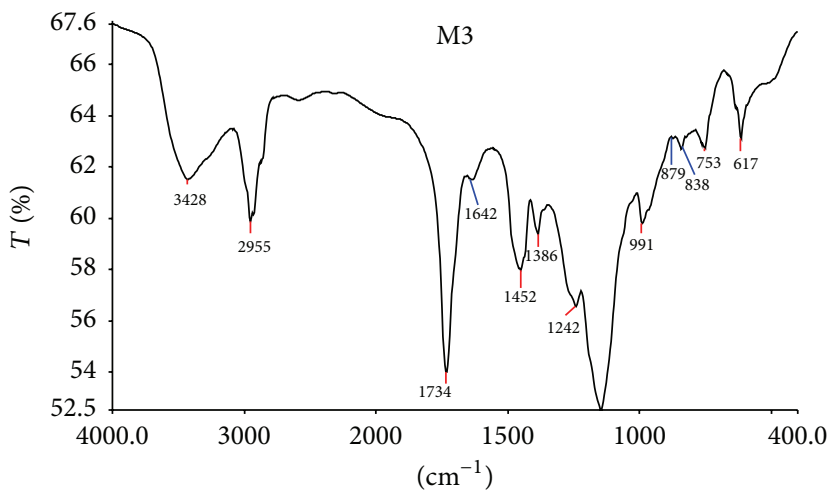

(c)

FIGURE 1: FTIR spectrum of the prepared terpolymers M1, M2, and M3.

$\mathrm{CH}$ appeared at $2960-2919 \mathrm{~cm}^{-1}$ and 2875 and $2851 \mathrm{~cm}^{-1}$, respectively.

The ${ }^{1} \mathrm{H}$ NMR spectra provide more evidence for the structure of the prepared terpolymers. The typical spectral for ${ }^{1} \mathrm{H}$ NMR is shown in Figure 2 and characteristic proton chemical shifts of the prepared terpolymers are recorded in Figure 3. The chemical shift at $\delta=1-0.9 \mathrm{ppm}$ is a result of protons in $\mathrm{CH}_{3}$ groups, $\delta$ at range $1.2-1.6 \mathrm{ppm}$ for protons in $\mathrm{CH}_{2}$ and $\delta=2.4 \mathrm{ppm}$ for proton in $\mathrm{CH}$ on the ethylhexyl group. The signals at $\delta 3.53-3.65 \mathrm{ppm}$ are assigned to $\mathrm{CH}_{3}$ groups attached to the $\mathrm{COO}$ side groups of MMA. The $\delta$ observed at $4.08 \mathrm{ppm}$ is assigned to protons in $\mathrm{CH}_{2}$ groups attached to the COO side group of 2-EHA. The prepared terpolymers are expected to have the following structure according the above characteristics as shown in Scheme 1.

3.2. Thermal Analysis. Thermal stability and thermal behavior of the prepared terpolymers were investigated using TGA/DTA and DSC measurements. The TGA/DTA thermograms obtained for all terpolymers are shown in Figure 4. As clearly seen, the main peak of thermal decomposition for all terpolymers started at $425^{\circ} \mathrm{C}$. The initial decomposition temperature $T_{i}$ and the residual mass after thermal decomposition are given in Table 1 . Besides, the terpolymers exhibited high thermal stability, which can be explained by multiple weak hydrogen bonding between the carbonyl groups $(\mathrm{C}=\mathrm{O})$ of the terpolymers and the hydrogen atoms of carboxyl

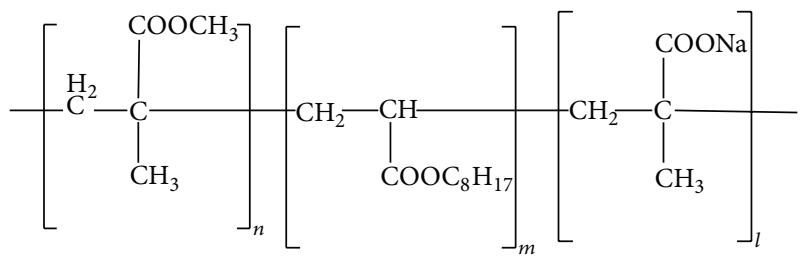

Scheme 1: Structure of the prepared terpolymer.

groups. In addition, thermal stabilities of terpolymers are decomposing in one step.

Thermal transitions of the terpolymers were determined by differential scanning calorimetry (DSC) analysis. As clearly seen, $T_{g}$ varies continuously with ratios of monomers in the terpolymer. To describe such type of composition dependence of $T_{g}$ of copolymers, the so-called Fox equation was used [22]:

$$
\frac{1}{T_{g}}=\frac{w_{1}}{T_{g 1}}+\frac{w_{2}}{T_{g 2}}+\frac{w_{3}}{T_{g 3}},
$$

where $T_{g}$ is the glass transition temperature of the terpolymer, $T_{g 1}, T_{g 2}$, and $T_{g 3}$ are the glass transition temperatures of the three homopolymers, and $w_{1}, w_{2}$, and $w_{3}$ are the weight fractions of the three repeat units in the terpolymers.

Differential scanning calorimetry is a conventional technique to judge the miscibility of a copolymer. The results of 


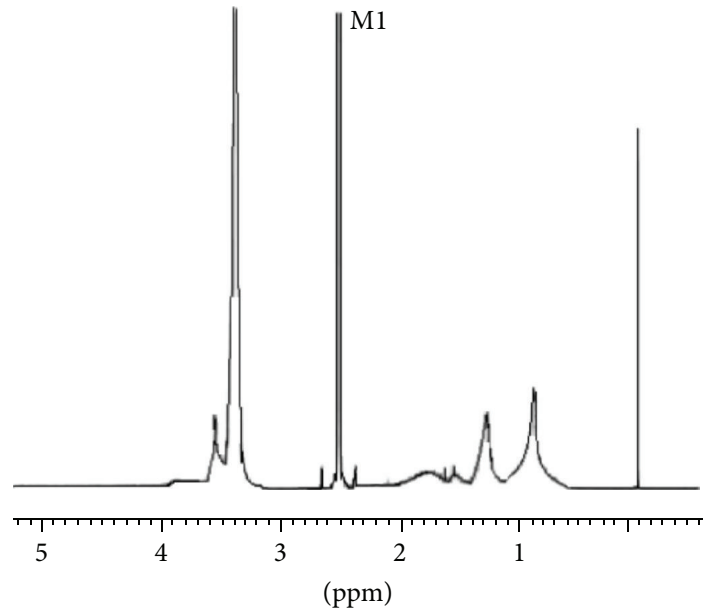

(a)

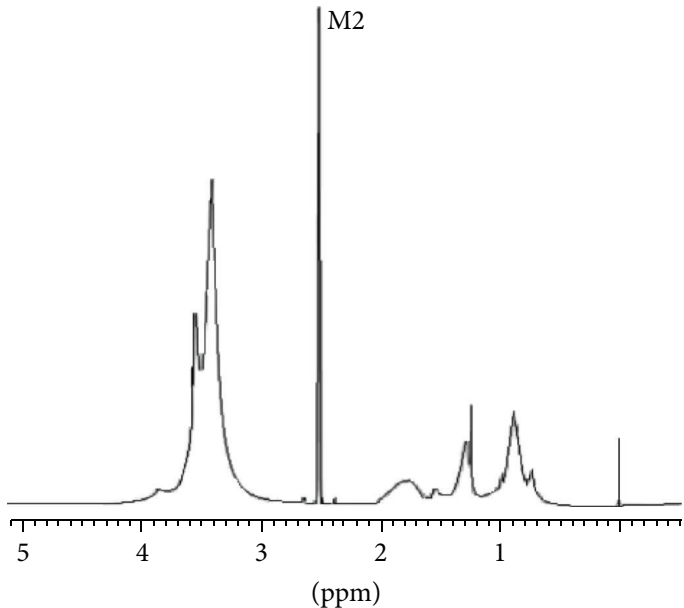

(b)

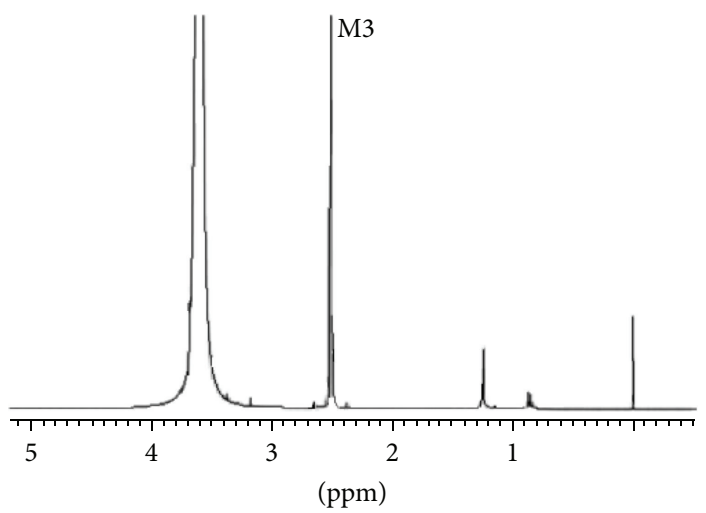

(c)

FIGURE 2: ${ }^{1} \mathrm{H}$ NMR of the prepared terpolymers M1, M2, and M3 in DMSO-D .

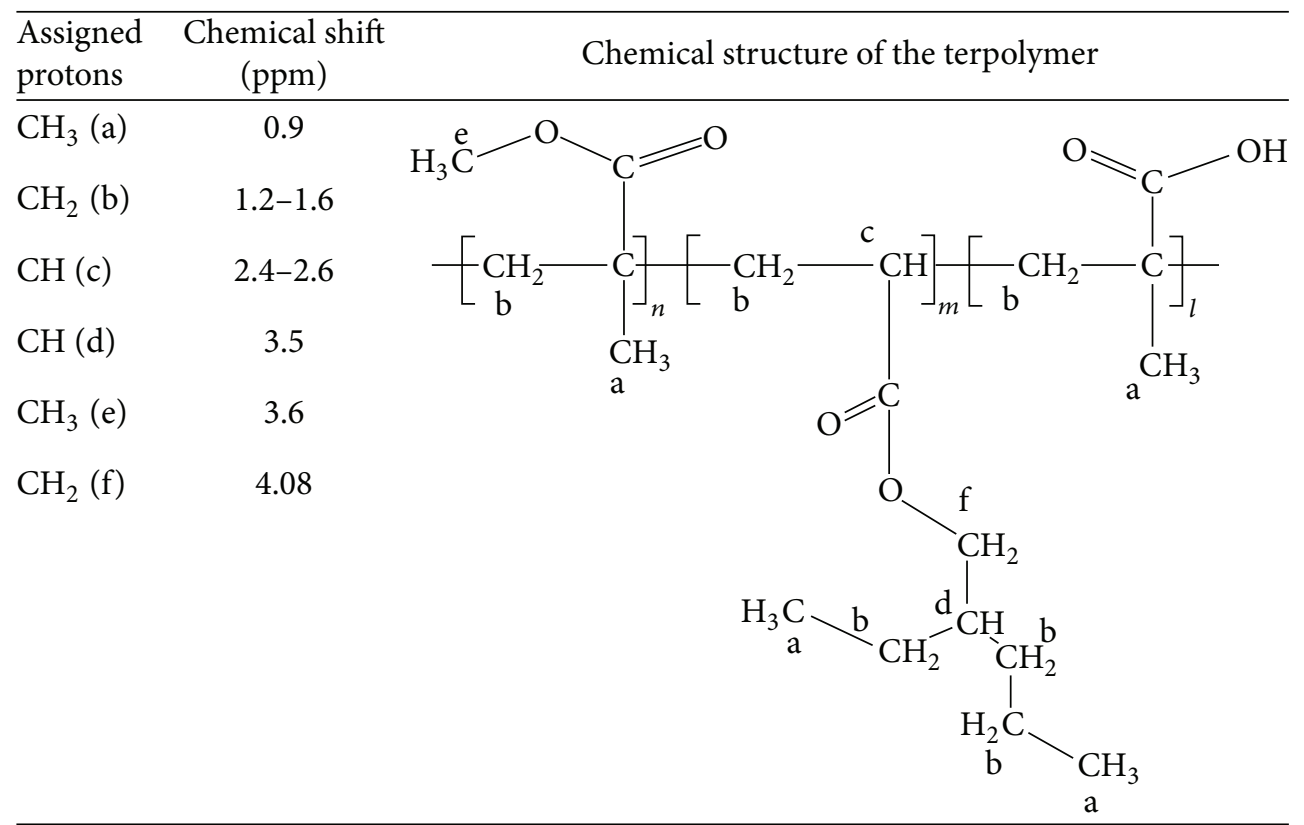

FIGURE 3: ${ }^{1} \mathrm{H}$ NMR chemical shifts of the prepared terpolymer. 
TABLE 1: Thermal analysis data for the prepared terpolymers.

\begin{tabular}{lccccc}
\hline Polymer & $T_{i}\left({ }^{\circ} \mathrm{C}\right)^{\mathrm{a}}$ & $T_{g}\left({ }^{\circ} \mathrm{C}\right)^{\mathrm{b}}$ & $T_{g}\left({ }^{\circ} \mathrm{C}\right)^{\mathrm{c}}$ & ${\text { Weight } \operatorname{loss}^{\mathrm{a}}(\%)}^{\text {Residual mass }^{\mathrm{a}}(\%)}$ \\
\hline M1 & 425 & 19.53 & 17.75 & 98.47 & 0.42 \\
M2 & 425 & 40.65 & 42.26 & 98.07 & 1.04 \\
M3 & 425 & 60.40 & 56.13 & 84.36 & 15.68 \\
\hline
\end{tabular}

${ }^{\mathrm{a}}$ The values were determined by TGA at a heating rate of $20^{\circ} \mathrm{C} / \mathrm{min}$.

${ }^{\mathrm{b}}$ Determined from DSC curves.

${ }^{c}$ Predicted using Fox equation.

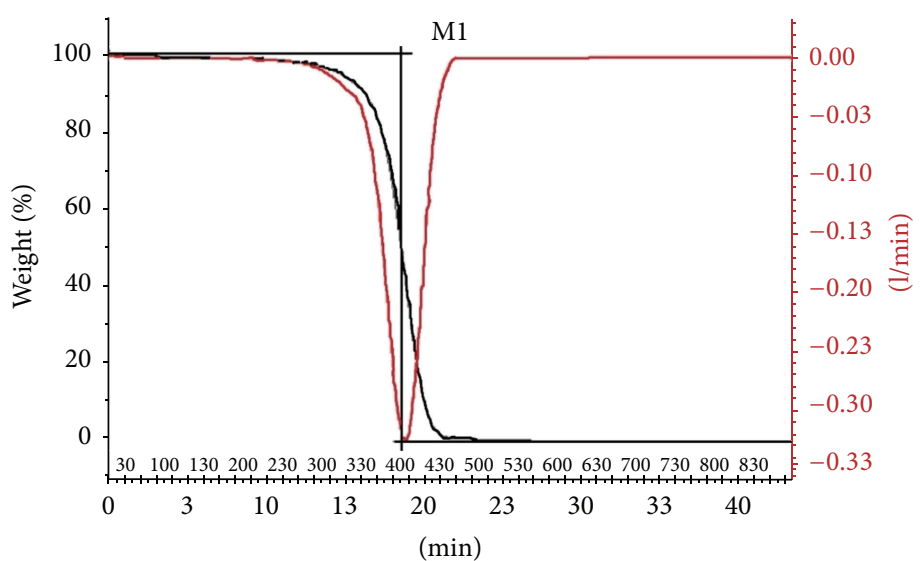

(a)

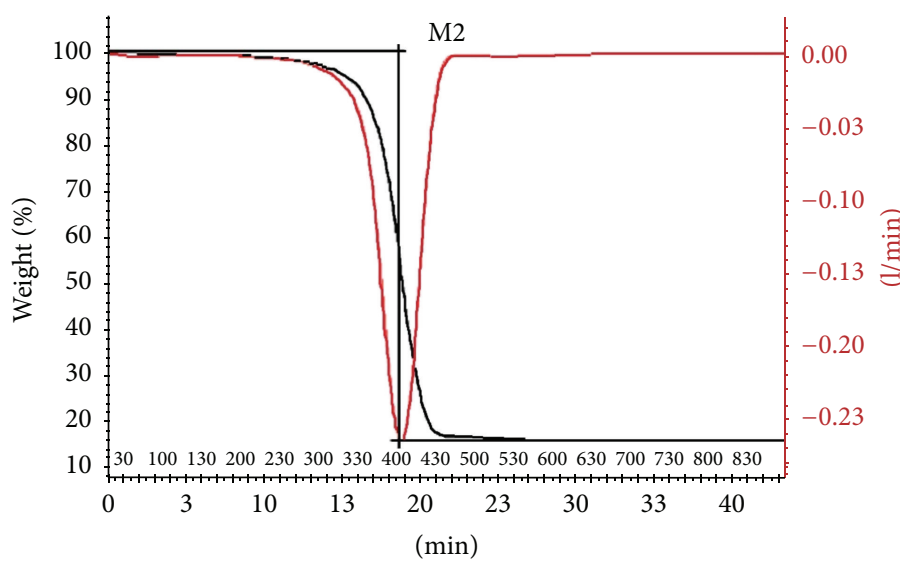

(b)

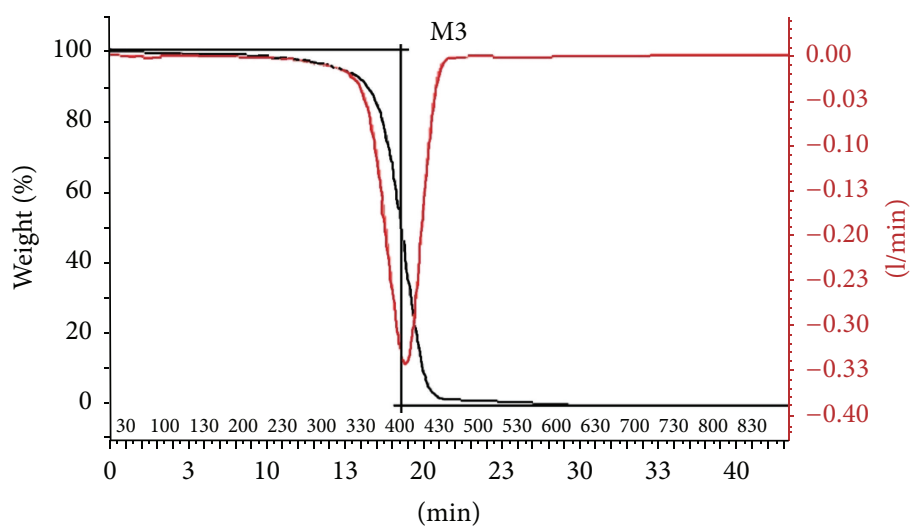

(c)

FIGURE 4: The TGA thermogram of terpolymers M1, M2, and M3. 


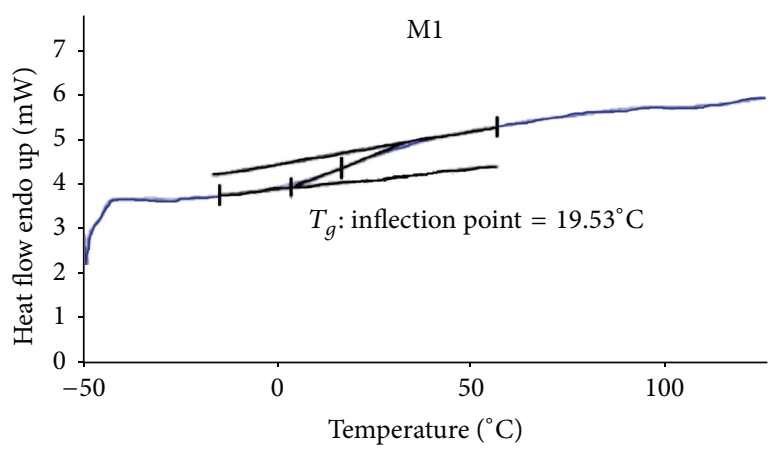

(a)

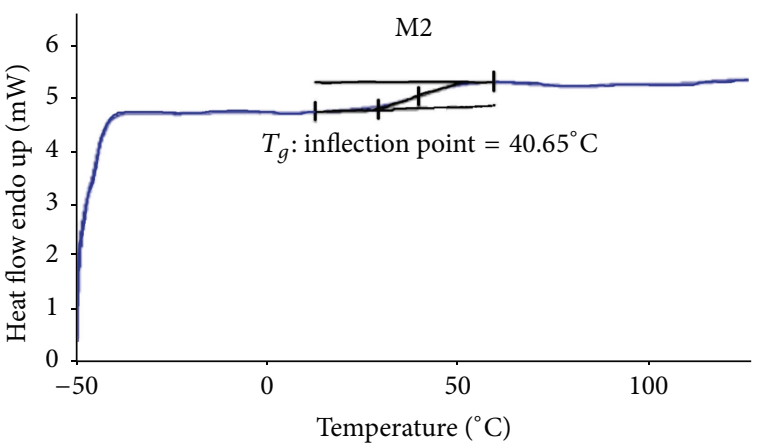

(b)

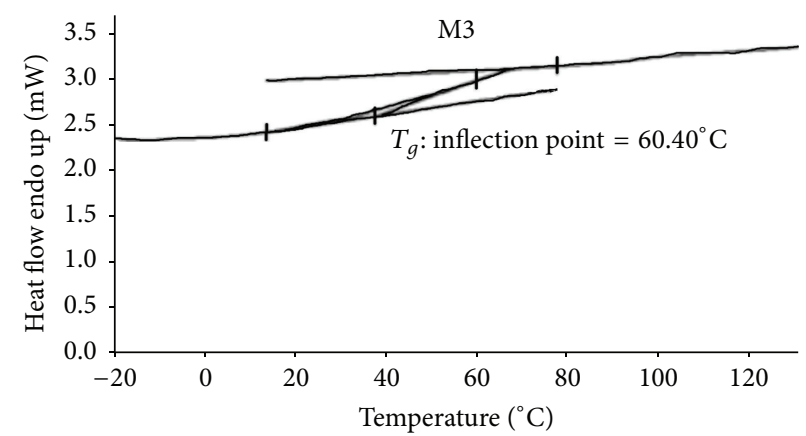

(c)

FIGURE 5: DSC thermograms of the prepared terpolymers M1, M2, and M3.

DSC analysis of copolymer are summarized in Table 1 and Figure 5 . The experimentally measured $T_{g}$ values are close to the predicted ones based on Fox equation. Generally, it is known that $T_{g}$ is directly proportional to cross-linking density and indirectly proportional to chain flexibility. Results are consistent with this statement. From Table 1, it can be seen that $T_{g}$ of terpolymers moves toward the lower temperatures as the 2-EHA increases. $T_{g}$ of the final terpolymers is changed by varying reaction time and temperature, most likely due to differences in reactivity ratios of the monomers, leading to different conversion rates and final terpolymer compositions in which the changes in the arrangement of the monomers in the final terpolymer occurred under several conditions. This process may introduce changes in the segmental motion or chain packing and it is described in detail for hydrogenbonded polymer complexes and some of the assumptions presented at that time may be applied to the homopolymers [23]. Hydrogen bonding between the branch chains decreases the mobility of the polymer chains.

3.3. Scanning Electron Microscope. Morphological structure of the terpolymers was investigated by scanning electron microscopy (SEM) as shown in Figure 6. SEM analysis exhibits the constituents of the prepared terpolymers, which clearly show that there is evident difference in quantities of monomers depending on the experimental stage. The ratio and type of the monomers are affected on the polymer particle morphology. As seen in Figure 6, creased surfaces with decrease in concentrations of MMA and increase in concentrations of 2-EHA were observed, which contain longer side chain (M1), whereas it was found that an increase in the concentrations of MMA resulted in higher porous spheres (M3). With similar quantity of MMA and 2-EHA (M2) the surface of the tripolymers was fine surface.

3.4. Characterization of Primer Films. Pot life is the length of time in which the flow properties (such as viscosity) of catalyzed syrup will not change within an acceptable application [24]. Pot life and cure time of primer syrup (M1, M2, and M3) are measured in the lab at an ambient temperature of $25^{\circ} \mathrm{C}$. Figure 7 shows a sharp decrease in pot life and cure time of primer syrup with increasing MMA in terpolymers backbone. Primer syrup (M1) with 65\% MMA gave longest pot life and cure time, while primer syrup (M3) with $80 \%$ MMA gave shortest pot life and cure time. It is well known that the pot life and cure time of acrylic syrups are affected by working temperature, mass of the mixed material, and the speed of the hardener [11].

The mechanical properties of the primer films with respect to the amount of MMA in terpolymers backbone are shown in Table 2. It can be seen that tensile strength increased with increasing amounts of MMA in the terpolymers backbone. This is presumably due to the increased hard segment contents (MMA) and partially cross-linking of carboxylic group (MAA) in the primer films. Internal ionic centers (MAA) also make positive contributions to the polymer properties by producing hydrogen bonding, greatly improving the mechanical strength of the materials [25]. 

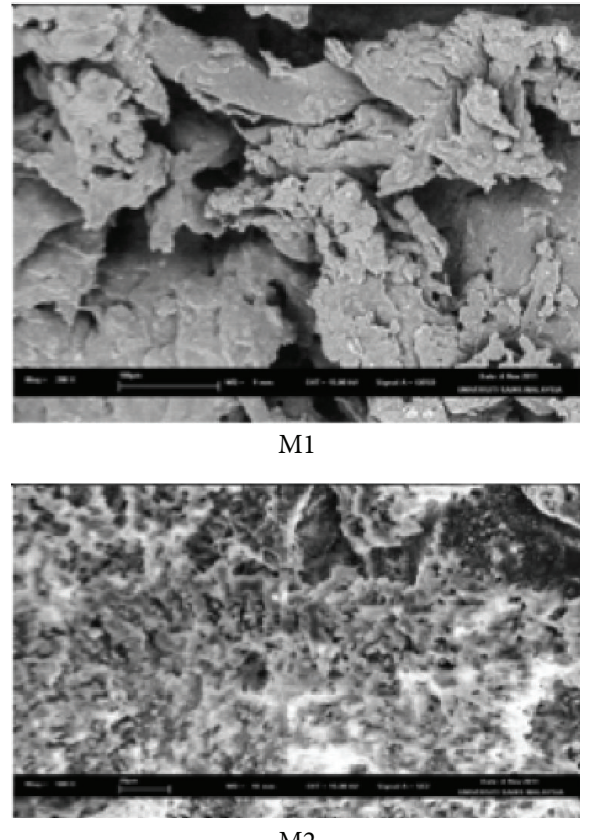

M2

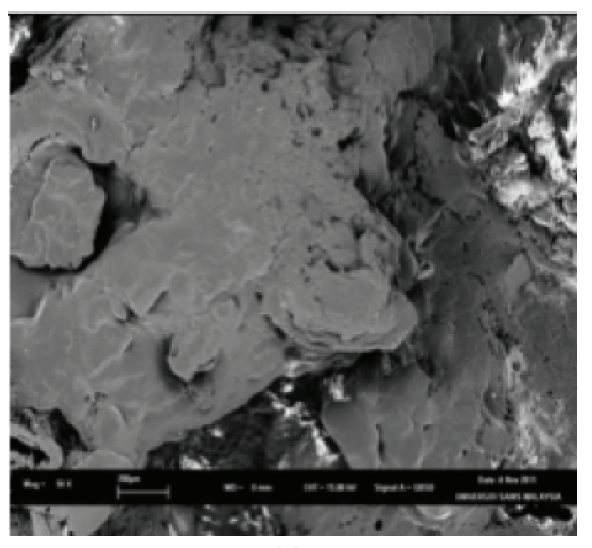

M3

FIGURE 6: SEM micrographs of the prepared terpolymers M1, M2, and $\mathrm{M} 3$.

TABLE 2: Mechanical properties of the primer cast films.

\begin{tabular}{lccc}
\hline Samples & M1 & M2 & M3 \\
\hline Tensile strength $\left(\mathrm{kgf} / \mathrm{cm}^{2}\right)$ & 190.125 & 273.36 & 324.13 \\
Elongation (\%) & 60.71 & 45.65 & 25.96 \\
Hardness (shore D) & 72 & 75 & 78 \\
\hline
\end{tabular}

However, the elongation at break of primer films increased with increasing 2-EHA amounts as shown in Table 2. Increasing soft segment (2-EHA) in terpolymer leads to softer primer films, which possess increased elongation at break and reduced tensile strength [26]. Also hardness shore (D) increased with increasing of MMA in terpolymer backbone of primer films as shown in Table 2. The surface hardness for primer film produced by terpolymer (M3) was found ca. 78, while that for primer film produced by terpolymer (M1) was found 72 .

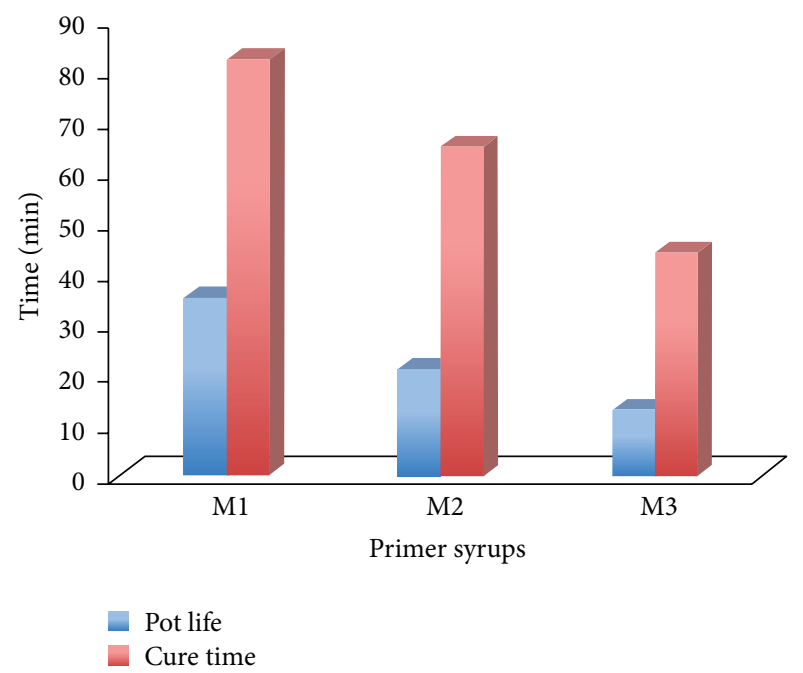

FIGURE 7: Pot life and cure time of primer syrup in presence of BPO and NDPT.

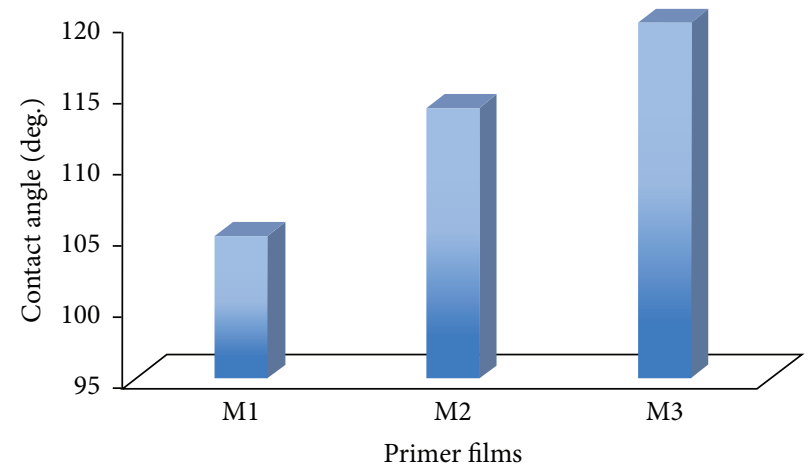

Figure 8: Contact angle of primer films M1, M2, and M3.

Advancing and receding contact angle measurements of the films cast from acrylic could provide more information on the hydrophilicity of dried cast films. A better understanding of the hydrophobicity of the cast films could be obtained from dynamic contact angle studies rather than from swelling studies. Figure 8 shows that the measured contact angle for a drop of water on primer surfaces increases with increasing MMA in terpolymer backbone. The hydrophobicity increased with the increasing amount of MMA. For example, M3 with $80 \%$ MMA gave the highest contact angle with 120 degrees, while M1 with 65\% MMA gave contact angle of 105 degrees. The results confirm that chain rigidity is a more significant factor in controlling the contact angle, because chain rigidity does not allow the ionic groups $(\mathrm{COOH})$ to come near the particle surface. As expected and in agreement with previously reported results by other authors [27], polymer surface exhibits hydrophobic character when sufficiently cross-linked and amount of polar of $\mathrm{COOH}$ decreases. On the other hand, the polar functional group, such as carboxylic acid (free) is expected to be reoriented out of the plan at the surface by rubbing, which in turn provides smaller water contact angle [28]. The contact angle of a well cross-linked 


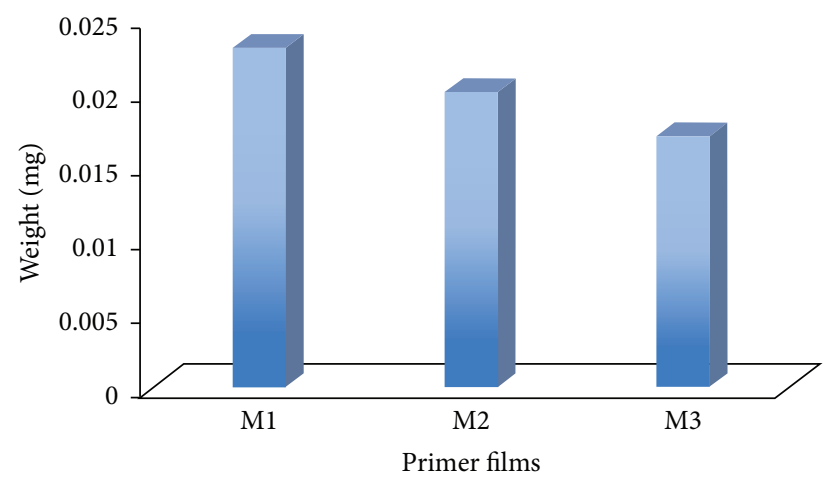

FIGURE 9: Water absorption test of primer films M1, M2, and M3.

film is higher than $90^{\circ}$ [29]. Generally, if the water contact angle is smaller than $90^{\circ}$, the solid surface is considered hydrophilic [29] and if the water contact angle is larger than $90^{\circ}$, the solid surface is considered hydrophobic [30].

The results of the water absorption tests reveal the dynamic wetting behavior of the primer films. The primer films show a very low absorption with the increase of content of MMA in terpolymer backbone, as shown in Figure 9. Films containing 80\% MMA and 15\% 2-EHA (M3) show lower water absorption than those containing 65\% MMA and 30\% 2-EHA (M1). The results showed that the water absorption of the films depends upon the composition of terpolymers. When the samples are immersed into water, the effect of buoyancy of water pushes the materials upwards since the surface contact angle is higher than $90^{\circ}$ [31]. This observation confirms the hydrophobic behavior of primer films.

Figure 10 shows the effect of terpolymer composition on bond strength between primer syrup and concrete substrate. From results, it can be seen that the bond strength of films containing 30\% 2-EHA was higher than that of film containing 15\% 2-EHA, while increasing the amount of MMA in terpolymer backbone reduced the bond strength of the films. The increase of bond strength is interpreted in terms of increasing soft segments (2-EHA) in the primer syrups, crosslinking, and bonding to the concrete substrate.

\section{Conclusion}

Terpolymers of (MMA:2-EHA:MAA) in three different ratios, about $30: 65: 5,47.5: 47.5: 5$, and $65: 30: 5$, were prepared and characterized in relation to IR, ${ }^{1} \mathrm{H}$ NMR, DSC, TGA, and SEM. TGA showed that all the terpolymers exhibited high thermal stability. However, DSC result showed that $T_{g}$ of terpolymer decreased with increasing 2-EHA. Acrylic syrups were prepared with $15 \mathrm{wt} . \%$ terpolymer and $85 \mathrm{wt} . \%$ MMA monomer polymerized by a dual initiating system containing BPO and NDPT. Acrylic syrups were applied as primer to concrete substrate. In primer syrups, mechanical properties increased with increasing MMA content in terpolymers backbone. On the contrary, bond strength between primer and concrete substrate increased with decreasing 2EHA. The best terpolymer composition, which produces primer with good bond strength with concrete substrate, was

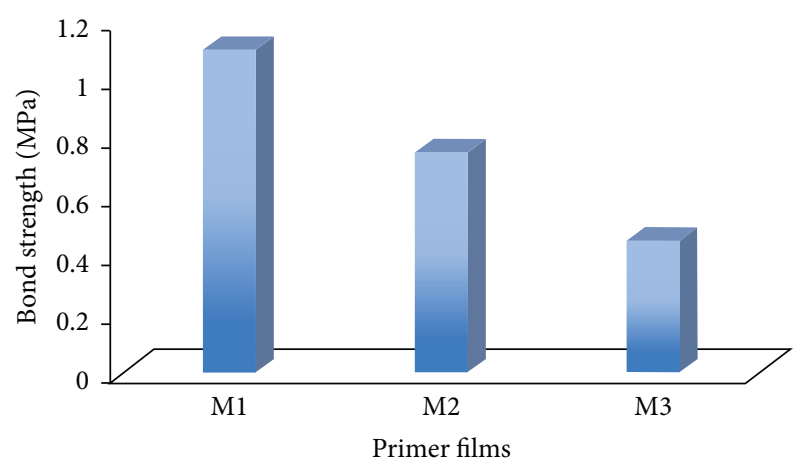

FIGURE 10: Bond strength test of primer films M1, M2, and M3.

65 wt.\% of 2-EHA. Pot life and cure time of acrylic syrups are affected by mass of the mixed materials.

\section{Competing Interests}

The authors declare that there are no competing interests regarding the publication of this paper.

\section{Acknowledgments}

The work was financially supported by Ministry of Science and Education of the Republic of Kazakhstan, Project no. 0115 PK01660.

\section{References}

[1] N. Moghadam, S. Liu, S. Srinivasan, M. C. Grady, M. Soroush, and A. M. Rappe, "Computational study of chain transfer to monomer reactions in high-temperature polymerization of alkyl acrylates," Journal of Physical Chemistry A, vol. 117, no. 12, pp. 2605-2618, 2013.

[2] J. Barth, M. Buback, G. T. Russell, and S. Smolne, "Chainlength-dependent termination in radical polymerization of acrylates," Macromolecular Chemistry and Physics, vol. 212, no. 13, pp. 1366-1378, 2011.

[3] P. A. Mueller, J. R. Richards, and J. P. Congalidis, "Polymerization reactor modeling in industry," Macromolecular Reaction Engineering, vol. 5, no. 7-8, pp. 261-277, 2011.

[4] A. Nurlybayeva, M. Sakhy, E.-S. Negim, E. Rustem, and A. Shinibekova, "Synthesis and research of copolymers on the basis of methyl methacrylate and their application in paint and varnish coverings," International Journal of Chemical Sciences, vol. 13, no. 2, pp. 922-934, 2015.

[5] V. Pathak, H. Saxena, A. Agrawal, and K. K. Bhardwaj, "Synthesis and characterisation of MMA-STY-AN terpolymer films," Oriental Journal of Chemistry, vol. 25, no. 4, pp. 847-850, 2009.

[6] N. Gatica, F. Natali, O. Alejandra, and R. Deodato, "Synthesis and characterization of functionalized vinyl copolymers I. structure-monomer reactivity relationship in copolymers containing N-vinyl-2-pyrrolidone moieties," Journal of the Chilean Chemical Society, vol. 50, no. 3, pp. 581-585, 2005.

[7] P. S. Vijayanand, C. S. J. Selvamalar, A. Penlidis, and S. Nanjundan, "Copolymers of 3,5-dimethylphenyl acrylate and methyl methacrylate: synthesis, characterization and determination of 
monomer reactivity ratios," Polymer International, vol. 52, no. 12, pp. 1856-1862, 2003.

[8] S. E. Park, M. Chao, and P. A. Raj, "Mechanical properties of surface-charged poly(methyl methacrylate) as denture resins," International Journal of Dentistry, vol. 2009, Article ID 841431, 6 pages, 2009.

[9] H. Abdul Samad and M. Jaafar, "Effect of polymethyl methacrylate (PMMA) powder to liquid monomer (P/L) ratio and powder molecular weight on the properties of PMMA cement," Polymer-Plastics Technology and Engineering, vol. 48, no. 5, pp. 554-560, 2009.

[10] N. J. Dunne and J. F. Orr, "Thermal characteristics of curing acrylic bone cement," ITBM-RBM, vol. 22, no. 2, pp. 88-97, 2001.

[11] N. Silikas, A. Al-Kheraif, and D. C. Watts, "Influence of P/L ratio and peroxide/amine concentrations on shrinkage-strain kinetics during setting of PMMA/MMA biomaterial formulations," Biomaterials, vol. 26, no. 2, pp. 197-204, 2005.

[12] B. Pascual, B. Vázquez, M. Gurruchaga et al., "New aspects of the effect of size and size distribution on the setting parameters and mechanical properties of acrylic bone cements," Biomaterials, vol. 17, no. 5, pp. 509-516, 1996.

[13] ISO, "Paints and varnishes-determination of the pot-life of liquid systems-preparation and conditioning of samples and guidelines for testing," DIN EN ISO 9514, 1994.

[14] ASTM, "Standard test methods for evaluating drying or curing during film formation of organic coatings using mechanical recorders," ASTM D5895-03, 2008.

[15] P. P. Chang, N. A. Hansen, R. D. Phoenix, and T. R. Schneid, "The effects of primers and surface bonding characteristics on the adhesion of polyurethane to two commonly used silicone elastomers," Journal of Prosthodontics, vol. 18, no. 1, pp. 23-31, 2009.

[16] M. J. Frangou, G. L. Polyzois, P. A. Tarantili, and A. G. Andreopoulos, "Bonding of silicone extra-oral elastomers to acrylic resin: the effect of primer composition," The European Journal of Prosthodontics and Restorative Dentistry, vol. 11, no. 3, pp. 115118, 2003.

[17] M. M. Hatamleh and D. C. Watts, "Bonding of maxillofacial silicone elastomers to an acrylic substrate," Dental Materials, vol. 26, no. 4, pp. 387-395, 2010.

[18] G. L. Polyzois, "A comparison of microwave and dry-heat curing methods on the bond strength of silicone facial materials applied to acrylic resin," Journal of Prosthodontics, vol. 5, no. 2, pp. 101-104, 1996.

[19] G. L. Polyzois, M. J. Frangou, and A. G. Andreopoulos, “The effect of bonding agents on the bond strengths of facial silicone elastomers to a visible light-activated resin," The International Journal of Prosthodontics, vol. 4, no. 5, pp. 440-444, 1991.

[20] C. Stamatacos-Mercer and T. L. Hottel, "The validity of reported tensile bond strength utilizing non-standardized specimen surface areas. An analysis of in vitro studies," American Journal of Dentistry, vol. 18, no. 2, pp. 105-108, 2005.

[21] R. M. Taft, S. M. Cameron, R. C. Knudson, and D. A. Runyan, "The effect of primers and surface characteristics on the adhesion-in-peel force of silicone elastomers bonded to resin materials," Journal of Prosthetic Dentistry, vol. 76, no. 5, pp. 515518, 1996.

[22] T. G. Fox, The Bulletin of the American Physical Society, vol. 1, p. $123,1956$.

[23] E. S. M. Negim, Z. A. Nurpeissova, R. A. Mangazbayeva, J. M. Khatib, C. Williams, and G. A. Mun, "Effect of $\mathrm{pH}$ on the physico-mechanical properties and miscibility of methyl cellulose/poly (acrylic acid) blends," Carbohydrate Polymers, vol. 101, no. 1, pp. 415-422, 2014.

[24] V. K. Joseph, Paint and Coating Testing Manual: 15th Edition of the Gardner Sward Handbook, ASTM International, Conshohoken, Pa, USA, 2012.

[25] D. S. Achilias and I. Sideridou, "Study of the effect of two $\mathrm{BPO} / \mathrm{amine}$ initiation systems on the free-radical polymerization of MMA used in dental resins and bone cements," Journal of Macromolecular Science A: Pure and Applied Chemistry, vol. 39, no. 12, pp. 1435-1450, 2002.

[26] D. Dieterich, "Aqueous emulsion, dispersions and solutions of polyurethanes: synthesis and properties," Progress in Organic Coatings, vol. 9, no. 3, pp. 281-340, 1981.

[27] A. Bhattacharya, W. J. Rawlins, and P. Ray, Polymer Grafting and Crosslinking, John Wiley \& Sons, New York, NY, USA, 2009.

[28] K. L. Mittal and K.-W. Lee, Polymer Surfaces and Interfaces: Characterization, Modification and Application, CRC Press, Utrecht, The Netherlands, 1997.

[29] F. L. Huang, Q. Q. Wang, Q. F. Wei, W. D. Gao, H. Y. Shou, and S. D. Jiang, "Dynamic wettability and contact angles of poly(vinylidene fluoride) nanofiber membranes grafted with acrylic acid," eXPRESS Polymer Letters, vol. 4, no. 9, pp. 551-558, 2010.

[30] W. J. van Ooij, D. Zhu, M. Stacy et al., "Corrosion protection properties of organofunctional silanes-an overview," Tsinghua Science and Technology, vol. 10, no. 6, pp. 639-664, 2005.

[31] F. Renate, S. Holger, A. Tobias, and A. Jenkins, Surface Design: Applications in Bioscience and Nanotechnology, Wiley-VCH, New York, NY, USA, 2009. 

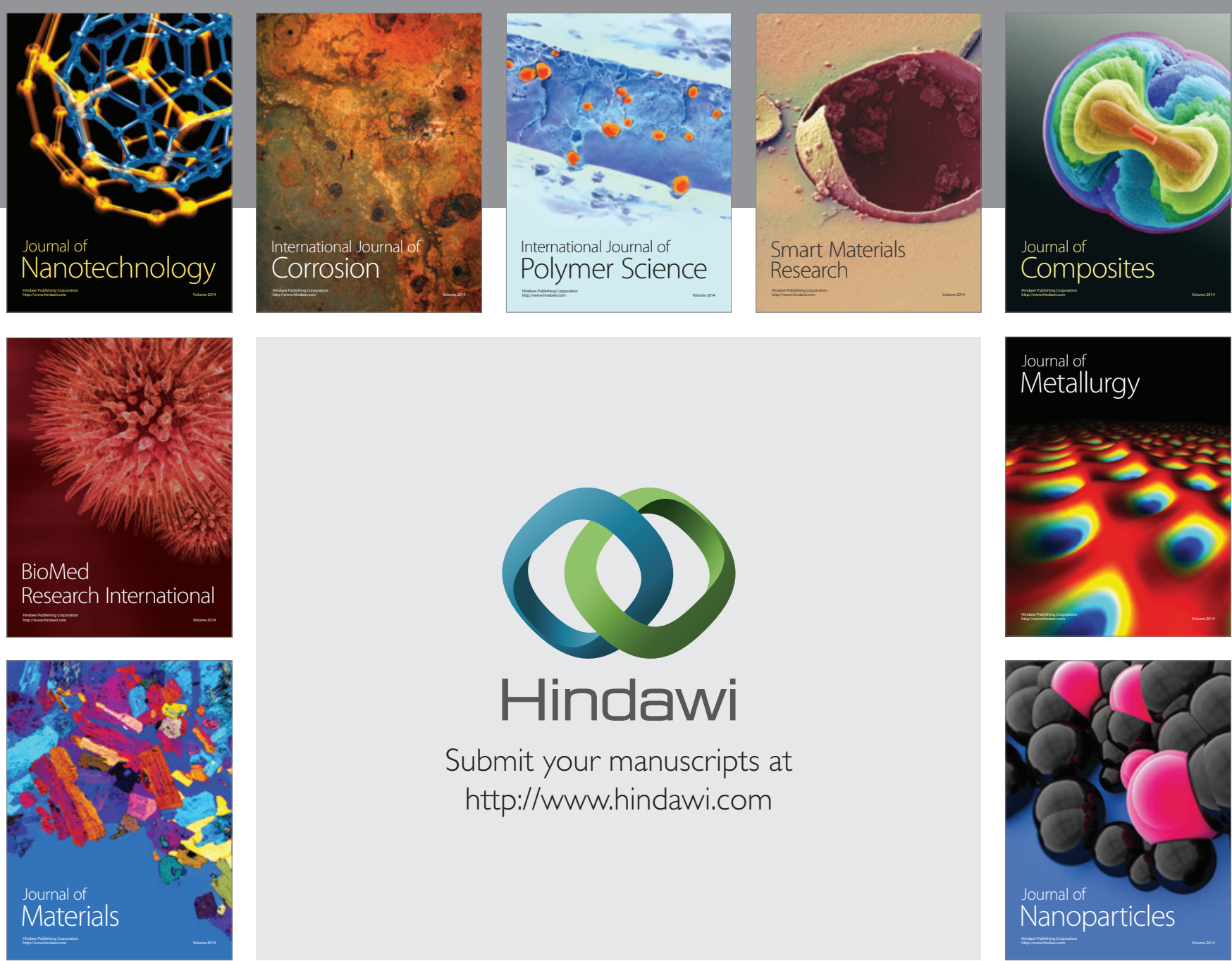

\section{Hindawi}

Submit your manuscripts at

http://www.hindawi.com

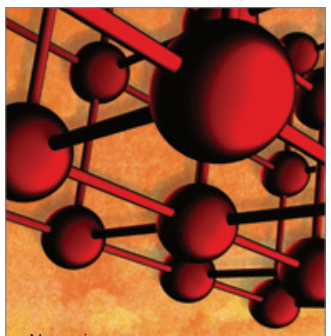

Materials Science and Engineering
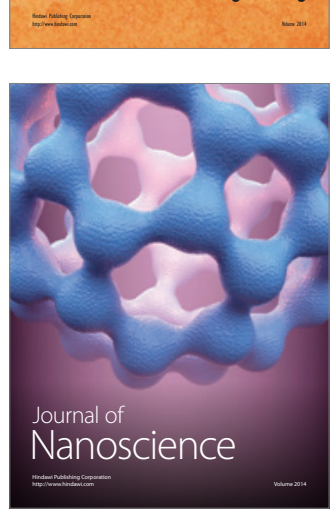
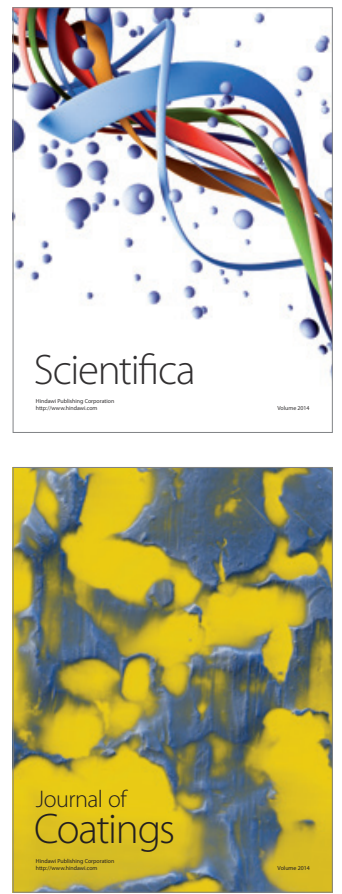
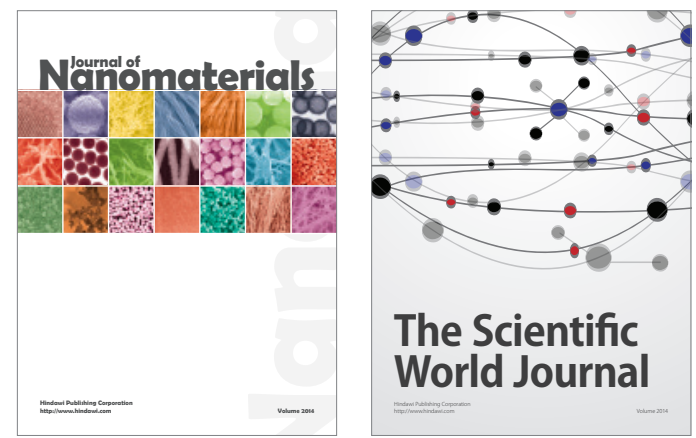

The Scientific World Journal
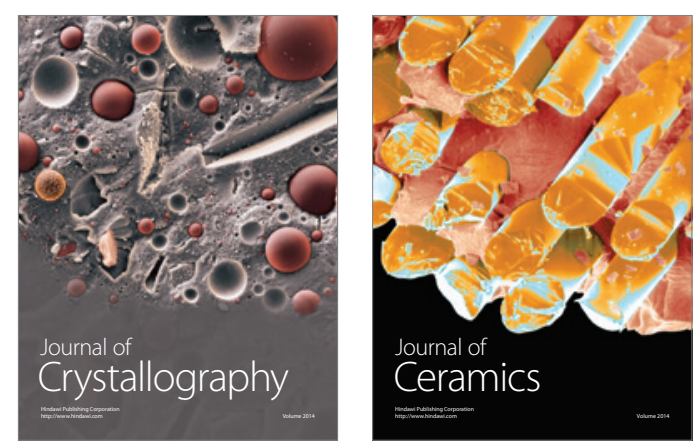
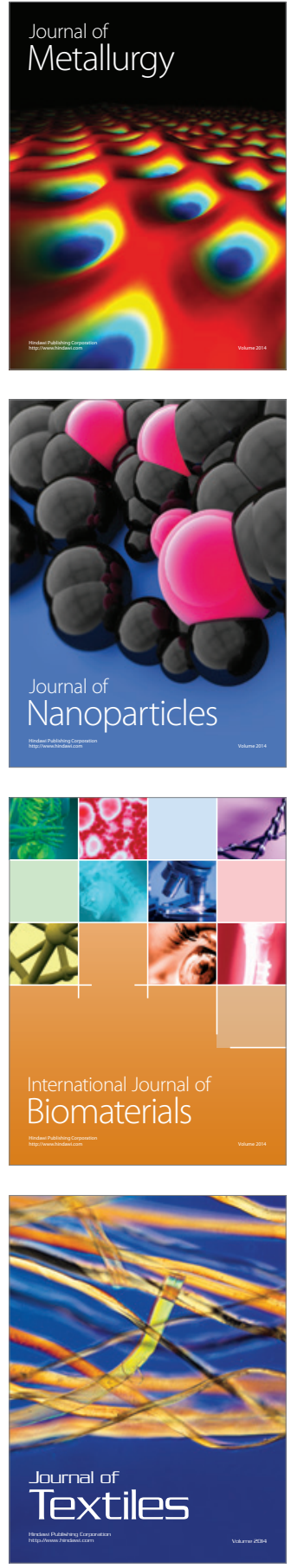